\title{
MACHADO MUSICAL: NOTAS SOBRE MÚSICA E ESCRITA
}

\section{KENNETH DAVID JACKSON}

Yale University

New Haven, Connecticut, Estados Unidos

Resumo: O presente estudo tem como objeto a influência da ópera e da música no método de composição do escritor. Para tanto, examina motivos ligados à música que serão desenvolvidos nos romances. Ao fim, propõe encontrar na ficção a encenação de uma cidade-teatro, na tradição barroca do grande teatro do mundo.

Palavras-chave: música; ópera; escrita; motivo.

\section{MUSICAL MACHADO: NOTES ON MUSIC AND WRITING}

\begin{abstract}
This study addresses the influence of opera and music on the creative method of the author by examining the motifs associated with music that are developed throughout the novels. The essay proposes that the author stages a city-theater, in the tradition of the baroque theater of the world.
\end{abstract}

Keywords: music; opera; writing; motif. 

foram um período de prática intensiva e de aprendizagem, da parte de um jovem ativo que cortejava atrizes e divas de ópera (MASSA, 2009). Compôs poemas louvando a soprano Carlotta Augusta Angeolina Candiani, que cantou na primeira apresentação de Norma, de Vincenzo Bellini, no Teatro São Pedro de Alcântara, em 17 de janeiro de 1844, enquanto Anne Charton-Demeur, Annetta Casaloni e Emmi La Grua, cada uma apoiada por um grupo de jovens entusiastas, se apresentaram em outros três teatros do Rio de Janeiro, a partir de 1859: o Ginásio, o São Januário e o Lírico Fluminense (MAGALDI, 2004). No segundo capítulo do romance $A$ mão e a luva, Machado descreve a competição entre as rivais: "Quem se não lembra, - ou quem não ouviu falar das batalhas feridas naquela clássica plateia do campo da Aclamação, entre a legião casalônica e a falange chartônica, mas sobretudo entre esta e o regimento lagruísta?" (ASSIS, 1979, p. 204). Percebe alguma coisa de diabólica, ligada a olhos, nos recitais de piano do grande Louis Moreau Gottschalk: "Citou-lhe um concerto de Gottschalk. O divino pianista melodiava ao piano; eles ouviam, mas o demônio da música levou os olhos de um para outro, e ambos esqueceram o resto" (ASSIS, 1979, p. 772). Aprendendo de óperas e peças europeias produzidas nos teatros do Rio de Janeiro, Machado tentou dramatizar a comédia humana com alegorias e arquétipos, características da ópera, empregando técnicas de imitação e mímica de suas linguagens e ritmos musicais. Machado não era o único autor a utilizar a ópera italiana nos seus enredos. Já em 1844 Martins Pena fez uma paródia da ópera Norma na comédia em um ato $O$ diletante, e José de Alencar, na peça $O$ demônio familiar, baseou um personagem na figura de Fígaro, da ópera bufa Il Barbiere di Siviglia, ossia L'inutile precauzione, de Rossini.

Os seus romances associam as óperas que assistiu nos teatros do Rio de Janeiro à psicologia e à situação de seus personagens. As referências começam a aparecer a partir do segundo romance, $A$ mão e a luva - "Não perdia teatro; mas só duas vezes teve o gosto de a ver: uma no Lírico, onde se cantava Sonâmbula, outra no Ginásio, onde se representavam os Parisienses, sem que ele ouvisse uma nota da ópera, nem uma palavra da comédia" (ASSIS, 1979, p. 219) -, passam por Dom Casmurro - "De noite fui ao teatro. Representava-se justamente Otelo, que eu não vira nem lera nunca; sabia apenas o assunto, e 
estimei a coincidência" (ASSIS, 1979, p. 934) - e chegam ao último romance, Memorial de Aires, que cita Fidélio, de Beethoven, e Tristão e Isolda, de Wagner. Barreto Filho (1947) detectou forte influência do teatro nos personagens, na montagem de entradas e saídas, nas atitudes e nos gestos, na relação entre os personagens e suas paixões e na sequência de cenas curtas. A série de cenas breves e desconexas permitiu que Machado, ao explorar a natureza e o caráter humanos, tratasse de temas profundos no contexto do teatro, tema avançado por Barreto Filho (1947, p. 57), quando afirma: "A sua crítica teatral é um dos ângulos pelos quais podemos perceber a evolução de seu espírito".

Repleta de observações críticas e sutis sobre o Rio de Janeiro do tempo do Império, a ficção machadiana é uma comédia humana e um teatro do mundo, que trata de temas encontrados em conhecidas obras de música, literatura e filosofia. Todos os romances têm como núcleo uma citação literária ou musical. O seu mundo de ficção abrange as classes sociais, as profissões e até a geografia, pano de fundo de uma cidade-teatro posta em cena com grande variedade de personagens e enredos. Como autor, Machado combina o drama neobarroco de tema e situação com a simetria neoclássica da escrita. O musicólogo Charles Rosen (1971) analisa o estilo neoclássico em Classical Style: Haydn, Mozart, Beethoven, trabalho que se aplica ao método de composição de Machado, na sua capacidade de coordenar diferenças ao encontrar equivalentes literárias para frase, ritmo e harmonia na música. Assim, forma um embasamento teórico capaz de apoiar a produção literária toda. Como autor, Machado é consciente dos paralelos entre escrever e compor, como notou em Dom Casmurro: "A música ia com o texto, como se houvessem nascido juntos, à maneira de uma ópera de Wagner" (ASSIS, 1979, p. 908). As tensões entre história e referência, autor e narrador, fonte e originalidade, dizer e significar, a sensualidade e a recusa, a voluptuosidade e a pureza são a química fundamental das sínteses literárias machadianas, comparáveis ao jogo da resolução harmônica na música neoclássica.

A avaliação de Rosen quanto à natureza do humor como função essencial do estilo neoclássico aproxima-se muito do método de composição e do ponto de vista de Machado:

Nas suas origens, o estilo era basicamente cômico. Não significa que o estilo não poderia expressar sentimentos de uma emoção profunda e trágica, mas o passo do ritmo clássico é o passo da ópera cômica, as frases são as frases 
da dança e as estruturas maiores são essas frases dramatizadas. (ROSEN, 1971, p. 95) ${ }^{1}$

O contraste de sentido entre a melodia e o acompanhamento (a ação e os bastidores), ou a mudança de voz ao usar instrumentos variados (personagens e falas), a presença de significados inesperados produzidos por modulações incomuns e material novo (capítulos vazios ou incongruentes), todos constituem o humor e wit cômico do estilo neoclássico. Apoiam aquilo que Rosen chama de bufonaria e alegre vivacidade do estilo neoclássico, qualidades certamente visíveis a Machado na atmosfera dos salões imperiais do Rio de Janeiro. Essas mesmas qualidades permeiam a escrita de Machado de Assis, complicadas e obscurecidas por uma crítica moral e ética.

Desde o começo da ficção, há uma notável consistência e estabilidade nos temas e motivos encontrados no mundo ficcional machadiano como um todo, como observou Barreto Filho (1947, p. 29): "O decorrer de sua vida foi uma continuada reflexão sobre alguns temas favoritos, que eram submetidos a muitas variações". O reino da imaginação opera dentro de um repertório rigorosamente delimitado, comparável à gama expressiva possível a uma partitura musical ou a um músico. A variabilidade do mundo barroco de ação é representada por uma linguagem racional e em um espaço que define os limites escolhidos pelo autor, que tende a elaborar uma série de conceitos, motivos, técnicas e estratégias retóricas fixos e recorrentes, com variações e em circunstâncias diferentes nos nove romances. A repetição de motivos-chaves foi óbvia para Eloy Pontes em 1939:

A volta às mesmas ideias e às mesmas cenas, em Machado de Assis, entretanto, não é deficiência verbal ou falha de espírito inventivo. É estigma, diátese, obsessão. Por vezes pequenos fatos, episódios mesquinhos, aspectos vulgares, colhidos de súbito, vistos de relâmpago, ficam-lhe nas câmaras escuras da memória, colados eternamente. (PONTES, 1939, p. 288)

\footnotetext{
${ }^{1}$ Tradução minha. No original: "The style was, in its origins, basically a comic one. I do not mean that sentiments of the deepest and most tragic emotion could not be expressed by it, but the pacing of classical rhythm is the pacing of comic opera, its phrasing is the phrasing of dance music, and its large structures are these phrases dramatized."
} 
Os temas seguem o aforismo de Quincas Borba: "[...] mas a vida, meu rico senhor, compõe-se rigorosamente de quatro ou cinco situações, que as circunstâncias variam e multiplicam aos olhos" (ASSIS, 1979, p. 800). O último romance, de 1908, continua semelhante argumento no aforismo, num 25 de fevereiro, "a vida tem os seus direitos imprescritíveis; primeiro os vivos e os seus consórcios; os mortos e os seus enterros que esperem" (ASSIS, 1979, p. 1184). O velho diplomata Aires comenta as simetrias que se encontram na vida, tais que certos acontecimentos separados no tempo podem ser identificados pelas qualidades subjacentes comuns:

A vida, entretanto, é assim mesmo, uma repetição de atos e meneios, como nas recepções, comidas, visitas e outros folgares; nos trabalhos é a mesma coisa. Os sucessos, por mais que o acaso os teça e devolva, saem muita vez iguais no tempo e nas circunstâncias; assim a história, assim o resto. (ASSIS, 1979, p. 1155)

\section{Otelo}

Machado desenvolve certos núcleos temáticos significativos, que adquirem uma atenção crescente e um poder acumulativo de um romance para outro. Um dos principais exemplos é a ópera Otelo, de Rossini, de 1816, muito representada no Rio de Janeiro (FARIA, 2008) desde a década de 1840, e baseada na peça Othello, de Shakespeare, de 1603. Otelo era uma das peças mais famosas do repertório do ator e empresário brasileiro João Caetano, cuja atuação certamente Machado de Assis conhecia, sendo Caetano marido da atrizdançarina-cantora Estela Sezefreda, referida no romance de Brás Cubas. No romance A mão e a luva, aparece a primeira referência, quando o personagem Estêvão assiste à ópera, "palmeando até romper as luvas, aclamando até cansarlhe a voz, mas acabando a noite satisfeito dos seus e de si." (ASSIS, 1979, p. 206) Observando a plateia, Estêvão associa a ópera a olhos e ao tema do Eros proibido: "Tinha agora os olhos pregados em outros olhos, não pardos como os dele, mas azuis, de um azul-ferrete, infelizmente uns olhos casados [...]" (ASSIS, on-line, 1979, p. 206). Já em Helena, volta uma referência à ópera associada à traição feminina, numa cena em que o pai de Helena alude à mãe dela, a esposa que o deixara por outro, enquanto esteve no Rio Grande do Sul: 
Poucos dias antes, a bordo, um engenheiro inglês, que vinha do Rio Grande para esta Corte, emprestara-me um volume truncado de Shakespeare. [...] "Ela enganou seu pai, diz Brabantio a Otelo, há de enganar-te a ti também." (ASSIS, 1979, p. 375)

Fica para Brás Cubas fazer piada filosófica ao se referir a Otelo. Acaba de ir ao Teatro de São Pedro para ouvir a Estela Sezefreda cantar quando, no intervalo, observa a jovem Nhã-loló, que não tira os olhos dele. Contemplando o vestido fino dela e sentindo-se bem com a atenção, Brás é levado a um dos seus devaneios filosóficos, comparando a nudez e a roupa. A nudez habitual, pensa ela, retardaria os sexos, enquanto o vestuário os atrai. Refere-se veladamente à sedução, aos ciúmes e à morte quando exclama: "Abençoado uso que nos deu Otelo e os paquetes transatlânticos!" (ASSIS, 1979, p. 603). Não é Brás o responsável pela morte de Nhã-loló, mas a febre amarela, que num capítulo subsequente põe fim ao subentendido erótico.

O romance que tem mais referências a Otelo é Quincas Borba, preparando a apoteose a vir em Dom Casmurro. Mais uma vez o tema amoroso é ligado a olhos, quando Rubião começa a louvar a formosura dos olhos de Sofia, enquanto ela, pasmada com a eloquência e ousadia de Rubião, procura uma maneira de responder sem ofender nem encorajar. Ela resolve fingir não entender as intenções de Rubião nem a situação de namoro em que se encontrou. Por essa confusão, no capítulo seguinte as estrelas se riem dela. No jogo entre inocência e erotismo, o narrador compara as estrelas a moças de quinze a vinte anos, "alegres, palreiras, rindo e falando a um tempo de tudo e de todos. Não nego que são castas; mas tanto pior - terão rido do que não entendem" (ASSIS, 1979, p. 672). Assim, o narrador ironiza: "Castas estrelas! É assim que lhes chama Otelo, o terrivel [...]" (ASSIS, 1979, p. 672) A referência é também terrível, pois a consequência de inocência e fingimento, mesmo real, pode ser a morte.

Em outra cena, Carlos Maria, depois de cortejar Sofia e se arrepender, pensa nas outras mulheres que o preferiam a qualquer outro e em seu desejo de apenas se deleitar com elas. Invoca a cena da morte de Desdêmona pelo inverso: como não quer nenhuma delas, ele é apenas objeto de admiração, sem amor nem ciúme: "Tais havia de provada honestidade que folgavam de o trazer ao pé de si, para gostar o contato de um belo homem, sem a realidade nem o perigo da culpa, - como o espectador que se regala das paixões de Otelo, e sai do teatro com as 
mãos limpas da morte de Desdêmona" (ASSIS, 1979, p. 709). O egoísmo e desinteresse de Carlos Maria o isenta de qualquer crime de paixão. Em Dom Casmurro, Bento também vai fingir estar isento de culpa.

Sofia se encontra com Maria Benedita, infeliz e querendo voltar à casa da mãe na roça. Para distraí-la, Sofia conta que já tem um noivo para ela, que deveria ser o Rubião, como já combinado com o marido Palha. Mas quando chega a hora de dizer o nome, não é capaz. "Ciúmes?", pergunta o narrador.

Seria singular que esta mulher, que não tinha amor àquele homem, não quisesse dá-lo de noivo à prima, mas a natureza é capaz de tudo, amigo e senhor. Inventou o ciúme de Otelo e o do cavaleiro Desgrieux, podia inventar este outro de uma pessoa que não quer ceder o que não quer possuir. (ASSIS, 1979, p. 710)

Quando Sofia, Palha e Rubião saem para o passeio à Tijuca, é Sofia quem cai do cavalo, "pensando em não sei quê." Estava com raiva, confusa e presa entre os dois homens: "Sofia caiu com graça. Estava singularmente esbelta, vestida de amazona, corpinho tentador de justeza. Otelo exclamaria, se a visse: 'Oh! minha bela guerreira!'" (ASSIS, 1979, p. 764). Sofia está às voltas com as suas paixões e vontades contrárias, manifestadas na confusão que provoca a caída do cavalo.

As referências a Otelo chegam ao ponto máximo em Dom Casmurro. No capítulo 72 o narrador imagina como seria a peça de Shakespeare se começasse pelo fim. Intima, dessa maneira, o desfecho da acusação de Bento contra Capitu logo antes de matá-la, ato a que alude obliquamente (CHALHOUB, 2018). Ao contrário de Otelo, Bento não se mata também; ao contrário, resolve escrever um romance para explicar e justificar o seu raciocínio, embora não passe de um Otelo que por ciúmes matou a sua Desdêmona. Explica, ainda, pateticamente, que o amor que tinha Bento por Capitu era porque ela simpatizava com o seu sofrimento, a sua tentativa de ser:

Nesse gênero há porventura alguma cousa que reformar, e eu proporia, como ensaio, que as peças começassem pelo fim. Otelo mataria a si e a Desdêmona no primeiro ato, os três seguintes seriam dados à ação lenta e decrescente do ciúme, e o último ficaria só com as cenas iniciais da ameaça dos turcos, as explicações de Otelo e Desdêmona, e o bom conselho do fino Iago: "Mete dinheiro na bolsa." Desta maneira, o espectador, por um lado, 
acharia no teatro a charada habitual que os periódicos lhe dão, porque os últimos atos explicariam o desfecho do primeiro, espécie de conceito, e, por outro lado, ia para a cama com uma boa impressão de ternura e de amor:

"Ela amou o que me afligira,

Eu amei a piedade dela." (ASSIS, 179, p. 884)

A última referência à opera no romance, e na prosa de Machado, ocorre quando Bento conta que foi à ópera e conheceu o drama de Otelo, diz ele pela primeira vez. Finge que é inocente das inferências eróticas, da mesma maneira que Estêvão, Brás e Sofia fingiram, nos respectivos romances. Também se acha inocente de traição, como se o ato de Otelo não tivesse passado antes pela sua cabeça: "De noite fui ao teatro. Representava-se justamente Otelo, que eu não vira nem lera nunca; sabia apenas o assunto, e estimei a coincidência" (ASSIS, 1979, p. 934). Ao matar Capitu, Bento imita Otelo e tenta reproduzir no seu romance a história de Otelo, como equivalente do drama shakespeariano.

\section{piano}

O piano é o instrumento por excelência nas obras de Machado, mencionado em todos os romances. No romance Helena, a filha do dr. Camargo é encontrada ao piano quando volta para casa, depois de ouvir a leitura do testamento do conselheiro Vale:

Quando Camargo chegou à casa, no Rio Comprido, achou sua mulher - D. Tomásia - meio adormecida numa cadeira de balanço e Eugênia, ao piano, executando um trecho de Bellini. Eugênia tocava com habilidade; e Camargo gostava de a ouvir. Naquela ocasião, porém, disse ele, parecia pouco conveniente que a moça se entregasse a um gênero de recreio qualquer. Eugênia obedeceu, algum tanto de má vontade. O pai, que se achava ao pé do piano, pegou-lhe nas mãos, logo que ela se levantou, e fitou-lhe uns olhos amorosos e profundos, como ela nunca lhe vira. (ASSIS, 1979, p. 275)

Nessa cena, o piano é apresentado como instrumento que expressa sentimentos de emoção íntimos, sobretudo em momentos quando palavras não convêm, como aquele em que Eugênia diz ao pai: "- Não fiquei triste pelo que 
me disse, papai - observou a moça -. Tocava por distrair-me. [...] Com a mão esquerda, assim mesmo de pé, extraiu vagamente três ou quatro notas das teclas suas amigas." (ASSIS, 1979, p. 276)

Em Dom Casmurro, Capitu vai ao piano quando não consegue tirar Bento do seu estado depressivo, como maneira de sair ou substituir o impasse emocional, segundo ele conta:

Deixei-me estar calado e aborrecido. Ela propôs-me jogar cartas ou damas, um passeio a pé, uma visita a Matacavalos; e, como eu não aceitasse nada, foi para a sala, abriu o piano, e começou a tocar; eu aproveitei a ausência, peguei do chapéu e saí. (ASSIS, 1979, p. 931)

Flora, em Esaú e Jacó, se refugiou no piano no momento da eclosão da república, quando caíram todas as instituições, e para evitar a escolha entre os dois noivos, Pedro e Paulo:

Não sonhou sequer com música; e, aliás, tocara antes algumas das suas páginas queridas. Não as tocou somente por gostar delas, senão por fugir à consternação dos pais, que era grande. [...] e meteu-se com o seu piano e as suas músicas. Escolheu não sei que sonata. Tanto bastou para lhe tirar o presente. A música tinha para ela a vantagem de não ser presente, passado ou futuro; era uma cousa fora do tempo e do espaço, uma idealidade pura. [...]

- Lá, lá, dó, ré, sol, ré, ré, lá - ia dizendo o piano da filha, por essas ou por outras notas, mas eram notas que vibravam para fugir aos homens e suas dissensões." (ASSIS, 1979, p. 1036)

Em Memorial de Aires, Tristão, que representa tematicamente um elo com a ópera de Wagner, já é pianista proficiente: "Tristão conhece música, e à noite, a pedido dela, executou ao piano um pedaço de Wagner, que ele achou muito bem" (ASSIS, 1979, p. 1134). Fidélia, na presença do conselheiro, toca de uma maneira que ele acha bem expressiva, como se quisesse contar alguma coisa que não podia ser dita em palavras: "Vendo que esta gostava da conversa, não lhe pedi música; ela é que foi de si mesma tocar piano, um trecho não sei de que autor, que se Tristão não ouviu em Petrópolis não foi por falta de expressão da pianista" (ASSIS, 1979, p. 1186). 


\section{A música e a prosa}

A música desempenha um papel central nos romances e nos contos. $\mathrm{O}$ conto "Um homem célebre" (Várias histórias) devolve o leitor ao 5 de novembro de 1875, a uma festa na casa da feliz viúva Camargo, a última, pois esta faleceu menos de dois meses depois. Ela pede ao obsequioso Pestana para tocar uma das suas famosas polcas. Pestana faz careta e vai devidamente ao piano, enquanto "[...] derramou-se pela sala uma alegria nova, os cavalheiros correram às damas" (ASSIS, 1979, vol. 2, p. 497) e o evento foi motivo de conversa na cidade. As senhoritas mal podiam acreditar que o jovem, "cor de rapé, cabelo negro, longo e cacheado, olhos cuidosos" (ASSIS, 1979, vol. 2, p. 497) era o compositor Pestana. Ele ficou cada vez mais aborrecido e vexado com a atenção e pediu licença para sair. Na rua, passou por outra casa em que uma das suas polcas estava sendo tocada e até encontrou na rua dois homens assobiando a mesma polca. Correu para casa, onde morava com um velho escravo que cuidou dele, numa casa que herdou do pai nos tempos de d. Pedro I. Na parede havia o retrato de um padre que dera para ele uma formação musical clássica, junto com retratos dos compositores Domenico Cimarosa, Mozart, Beethoven, Christoph Gluck, Bach, Robert Schumann e alguns outros. O piano ficou aberto, como altar, e o texto sagrado era uma sonata de Beethoven. Pestana vivia apenas para ser compositor clássico. Passou a tarde a olhar os retratos, indo ao piano, esperando pela inspiração que nunca chegava. Até as estrelas pareciam a ele como notas musicais à espera de um compositor. Enquanto gozava da fama e da atenção de jovens moças por causa das polcas famosas, só ficava mais desesperado, perguntando aos céus por que não podia compor uma página imortal e ideal.

Em A mão e a luva, residentes do interior do estado vêm à capital à procura da música de Otelo, de Rossini, cantada pela soprano famosa Emmi La Grua: "Hoje mesmo - respondeu o colega -; venho sequioso de música. Vassouras não tem Lagrua nem Otelo..." (ASSIS, 1979, p. 206). Em Esaú e Jacó, aos quinze anos Flora é graciosa, retraída e modesta, passando dias inteiros ao piano com sua música: "Gostava de música, e mais do piano que do canto. Ao piano, entregue a si mesma, era capaz de não comer um dia inteiro" (ASSIS, 1979, p. 986). Flora toca algumas de suas peças preferidas no piano como maneira de escapar do

momento presente, ao se refugiar numa dimensão de eternidade. Às vésperas da revolução que derrubou a monarquia, no clima de consternação dos pais e das 
manobras políticas dos pretendentes, Pedro e Paulo, Flora foge para dentro da música. Machado descreve a sua atitude como uma sinestesia: "Sem palavras, como um romance ao piano" (ASSIS, 1979, p. 972). O conselheiro Aires não conseguiu identificar a sonata, mas notou que, ao tocar, Flora ficou longe do tempo presente. Pode-se conjeturar que Flora estava tocando uma rapsódia ou um impromptu, em vez de uma sonata, porque Aires associa a falta de forma da peça à desarmonia caótica do momento político, sem governo definitivo. As notas vindas do além - "lá, lá, dó, ré, sol, ré, ré, lá" - do piano soavam aos ouvidos de Aires como oximoro, a expressão perfeita de uma ausência presente, pois sabia que Flora sofria de visões breves e súbitas (ASSIS, 1979, p. 1036). Aires compara a música de Flora à "anarquia da inocência primitiva naquele recanto do Paraíso que o homem perdeu por desobediente, e um dia ganhará, quando a perfeição trouxer a ordem" (ASSIS, 1979, p. 1037). A música de Flora parece, ao não musical Aires, eternamente sem forma, compreensível apenas quando o seu

primitivismo desgovernado - comparado por ele ao ciclo de revoluções políticas - se resolver numa ordem geral, permanente, perfeita e estável.

Mesmo assim, o interesse maior do conselheiro, em Memorial de Aires, é na natureza das emoções de Fidélia quando toca piano, com uma expressão notável. Aires duvidava se essa música não seria talvez uma homenagem a uma realidade querida que se perdeu com o tempo e na cova, a um mundo mais dele do que Tristão. Da mesma maneira que Rubião esperava encontrar a sua Sofia quando os dois olhavam para o Cruzeiro do Sul, Aires sente que a sua possível união com Fidélia pertence a um fragmento de eternidade ocupado apenas por almas, mortos e ausentes: "A eternidade é mais longe, e ela já lá mandou outros pedaços da alma; vantagem grande da música, que fala a mortos e ausentes" (ASSIS, 1979, p. 1186).

\section{Brás Cubas, o basso buffo}

A ópera cômica, opera buffa, apresentada nos teatros do Rio de Janeiro, deu a Machado uma referência genérica para as Memórias póstumas de Brás Cubas; nesse romance, a descrição do cômico segundo Rosen (1971), como qualidade essencial do estilo neoclássico na música, pode ser aplicada com sucesso à opera buffa do autor carioca. Servindo muitas vezes de intermezzi entre atos de opera seria, essas óperas breves de entretenimento popular servem 
de contraponto aos graves temas e enredos apresentados ao seu redor. Cantado com o ritmo da fala cotidiana, o gênero se distingue musicalmente pela claridade da articulação, distinção acentuada entre tonalidades, local de ação incongruente, duplos sentidos, modulação de sentido ao sem sentido, irregularidade rítmica da frase, uso de conversação engenhosa como material temático e atmosfera de vivacidade civilizada. Nas Memórias póstumas de Brás Cubas, os fragmentos mais aventurosos podem ser considerados equivalentes a tonalidades; as interrupções e locuções non sequitur, à irregularidade rítmica; a marginalização sociopolítica, à incongruência; as alusões literárias e históricas, a trocadilhos, tudo representado com charme pessoal, um wit tipo inglês e direcionado ao leitor com o fim de preservar a continuidade e a forma do material melódico, ou seja, a frase e a fala. Brás é o basso buffo dessas pequenas óperas, o personagem cômico que se especializa em textos trava-línguas e travacérebros; os capítulos seguem numa sucessão rápida de ritmos e estilos, com o fim específico de entretenimento, capturando a atenção do leitor.

O objetivo musical da memória-ópera, em termos da sua composição, é chegar a uma resolução da tensão harmônica por meio de um retorno eventual à chave tônica. Mas na conclusão, ou último recitativo das Memórias póstumas, Brás se queixa da vida por tê-lo privado de um herdeiro. A filosofia fatalista de além-túmulo substitui a vivacidade de uma resolução harmônica, deixando a melodia principal sem apoio harmônico estrutural, para acabar numa chave menor instável, morosa e vexada. Com tal fim, Machado mais uma vez muda as convenções do gênero, pois a tradição requer modulação a uma chave maior para voltar, preservar ou restaurar a comédia; Brás comentara no prólogo sobre as "rabugens de pessimismo" que o levaram a alterar a expressão do gênero: "Há na alma deste livro, por mais risonho que pareça, um sentimento amargo e áspero, que está longe de vir dos seus modelos" (ASSIS, 1979, p. 512). No melhor estilo buffo, Brás atribui o contraste à "pena da galhofa e a tinta da melancolia" (ASSIS, 1979, p. 513). Volta a incluir a soprano Candiani no seu romance, quando Brás quer desviar a zanga e a queixa de Virgília:

- Nada menos que um camarote.

- Para a Candiani?

- Para a Candiani.

Virgília bateu palmas, levantou-se, deu um beijo no filho, com um ar de alegria pueril, que destoava muito da figura [...] (ASSIS, 1979, p. 577) 
Entre os capítulos que substituem palavras por outras formas de expressão, há "O velho diálogo de Adão e Eva" (ASSIS, 1979, p. 570), que consiste inteiramente de marcas de pontuação; o capítulo "Epitáfio", que reproduz a lápide funerária de Nhã-loló no cemitério (ASSIS, 1979, p. 621); e "Inutilidade" (ASSIS, 1979, p. 626), que usa apenas uma frase para confessar a sua inutilidade no romance, aparentemente reflexão fora do lugar. Esse procedimento da parte do autor pode ser defendido como tipo de engenho, ou wit inglês, que desfaz lugares comuns e leva a percepções inesperadas. Na música, Rosen descreve um efeito comparável, dentro do estilo neoclássico, que encontra sentido na irregularidade:

Se, surpreendentemente, a inteligência e sagacidade podem fazer senso de não-senso, uma modulação clássica fornece a fórmula: só é preciso [...] um momento em que o significado de uma nota é posto em dúvida [...] indispensável, é claro, é a irregularidade do ritmo da frase [...] e o tom de conversação inteligente que caracteriza a matéria temática (ROSEN, 1971, p. 52$)^{2}$

Aplicada à retórica e à literatura, a palavra que coordena dois significados díspares provocaria confusão na concordância verbal, subordinando o sentido à sintaxe e interrompendo uma leitura linear. Depois de um breve período de ajuste, aquilo que ficara fora do lugar - a bufonaria e o jogo cômico - agora parece expressar perfeitamente o engenho sutil que o autor pretendia. $\mathrm{O}$ procedimento pode ser comparado à modulação a uma chave distante, uma lógica musical inesperada, antes da volta à chave tônica.

\section{A vida é uma ópera}

O capítulo "A ópera", em Dom Casmurro, prova que a alegoria é fundamento do mundo literário machadiano e fonte de suas tensões criativas.

\footnotetext{
2 Tradução minha. No original: "If wit can take the form of a surprising change of nonsense into sense, a classical modulation gives a splendid formula: all we need [...] is one moment when we are not sure what the meaning of a note is [...] indispensable, of course, is the irregularity of the phrase rhythm [...] and the tone of witty conversation that characterizes the thematic material."
} 
Propõe um mito paralelo ao Gênesis para explicar a criação do mundo e a música composta, encenada, orquestrada e tocada numa competição entre Deus e o Diabo. "A vida é uma ópera", disse o velho tenor italiano Marcolini ao jovem Bento, narrador do mito. A "abertura" a essa grande ópera segue a metáfora da vida como teatro: até esse momento, tudo na vida de Bento era, dizia, como preparação para uma entrada no palco, colocando maquiagem e fantasia, iluminando o palco, afinando os violinos, preparação para o começo da ópera da sua vida. Enquanto olhava velhos retratos dos pais, na época do seu casamento, diz Bento, "comecei por não ser nascido" (ASSIS, 1979, p. 817). Tal estado de potencialidade se aplica à vida como luta para nascer, por extensão aos tenores, barítonos e baixos que lutam pela soprano, e a contralto e soprano que lutam pelo tenor na grande ópera, com os seus coros, balés e orquestras. Depois de um copo de chianti, o italiano revela a história musical da criação:

Deus é o poeta. A música é de Satanás, jovem maestro de muito futuro, que aprendeu no conservatório do céu. Rival de Miguel, Rafael e Gabriel, não tolerava a precedência que eles tinham na distribuição dos prêmios. Pode ser também que a música em demasia doce e mística daqueles outros condiscípulos fosse aborrecível ao seu gênio essencialmente trágico. Tramou uma rebelião que foi descoberta a tempo, e ele expulso do conservatório. Tudo se teria passado sem mais nada, se Deus não houvesse escrito um libreto de ópera, do qual abrira mão, por entender que tal gênero de recreio era impróprio da sua eternidade. Satanás levou o manuscrito consigo para o inferno. Com o fim de mostrar que valia mais que os outros e acaso para reconciliar-se com o céu -, compôs a partitura, e logo que a acabou foi levá-la ao Padre Eterno. (ASSIS, 1979, p. 817-818)

A ópera é abrangente, todos os elementos estão incluídos - fogo, água, ar e terra - e a produção continua enquanto dure a vida na terra. A partitura é conflitiva aqui, repetitiva ali, com passagens obscuras, e os coautores nunca concordam. Benedito Nunes (1989, p. 20) vê na ópera de Marcolini as contradições da existência humana na ótica do mito e da metafísica, o contraste dramático entre forças opostas e irredutíveis, nunca capazes de produzir uma harmonia perfeita. A ópera cômica de Marcolini, divina e profana, inverte a história bíblica das origens, até os anjos brigam, dessa maneira espelhando a narrativa de Bento, na qual acontecimentos trágicos são muitas vezes tratados comicamente, e situações cômicas, tragicamente. Bento leva adiante a 
comparação, ao alegar que a ópera e a tragédia de Shakespeare espelham a sua vida; invoca Otelo para justificar a variação pessoal do tema. A referência à peça shakespeariana The Merry Wives of Windsor apresenta mais um modelo, com Capitu e Sancha no papel das esposas felizes e Escobar e Bento como Falstaff e Ford, o sedutor potencial e o marido ciumento sem razão. Bento e Marcolini, os dois, insistem absurdamente que as suas testemunhas são "a verdade pura e última" (ASSIS, 1979, p. 819), porém Bento sabe perfeitamente que a ópera apenas parece ser verdadeira. Pensando como advogado, fala em aforismo da "verossimilhança, que é muita vez toda a verdade" (ASSIS, 1979, p. 819), frase que denuncia até que ponto não entendeu a interação entre verdade e invenção na ópera, e talvez na própria narrativa. Está decidido que vai fazer um papel como personagem na própria ópera, ostentando os próprios adornos e a subjetividade, ou não sabendo ou escolhendo ignorar os defeitos no libreto que fazem dele, da mesma maneira que a sua narração, um fracasso hermenêutico.

Tudo na prosa de Machado de Assis serve a um grande teatro barroco do mundo, ou ópera cômica sobre a condição humana, como se Machado encenasse o aforismo proclamado por Luís Batista em Ressurreição: "A vida é uma ópera bufa com intervalos de música séria" (ASSIS, 1979, p. 182). Se o mundo é palco de ópera, então a representação é o nosso modo de ser; e a música substitui as palavras para explicar o mundo. O tenor italiano em Dom Casmurro igualmente confere que "A vida é uma ópera e uma grande ópera" (ASSIS, on-line, Dom Casmurro, capítulo 9). É a representação que para ele é a pura verdade, o Gênesis em que a música substitui a palavra:

Um dia, quando todos os livros forem queimados por inúteis, há de haver alguém, pode ser que tenor, e talvez italiano, que ensine esta verdade aos homens. Tudo é música, meu amigo. No princípio era o dó, e o dó fez-se ré, etc.. (ASSIS, 1979, p. 819)

Na sua penúltima década de vida, Machado de Assis pensou em declarar: "Quero saber de música, só música, tão somente música" (ASSIS, 1979, vol. 3, p. 714). 


\section{Referências}

ASSIS, Machado de. Obra completa. Rio de Janeiro: Nova Aguilar, 1979.

BARRETO FILHO, José. Introdução de Machado de Assis. Rio de Janeiro: Agir, 1947.

CHALHOUB, Sidney. Apego à desigualdade: Machado de Assis, intérprete do Brasil. In: AMERICAN PORTUGUESE STUDIES ASSOCIATION INTERNATIONAL CONFERENCE, 11., 19 out. 2018, University of Michigan. Comunicação.

FARIA, João Roberto. Machado de Assis: do teatro. São Paulo: Perspectiva, 2008.

JACKSON, K. David. Machado de Assis: a Literary Life. New Haven: Yale, 2015.

MAGALDI, Cristina. Music in Imperial Rio de Janeiro: European Culture in a Tropical Milieu. Lanham, Md.: Scarecrow Press, 2004.

MASSA, Jean-Michel. A juventude de Machado de Assis. São Paulo: Unesp, 2009.

NUNES, Benedito. Machado de Assis e a filosofia. Travessia, n. 19, p. 7-23, 1989.

PONTES, Eloy. A vida contraditória de Machado de Assis. Rio de Janeiro: José Olympio, 1939.

ROSEN, Charles. Classical Style: Haydn, Mozart, Beethoven. New York: Viking, 1971.

KENNETH DAVID JACKSON é professor de literatura luso-brasileira na Universidade de Yale. Autor de A prosa vanguardista na literatura brasileira: Oswald de Andrade (1978); A vanguarda literária no Brasil (1998), Adverse Genres in Fernando Pessoa (2010) e Machado de Assis: A Literary Life (2015). Editor da Oxford Anthology of the Brazilian Short Story (2006); Haroldo de Campos: A Dialogue with the Brazilian Concrete Poet (2005); e Joaquim Nabuco e Yale, um dos volumes de Conferências sobre Joaquim Nabuco (2010). E-mail: k.jackson@yale.edu

Recebido: 30.10 .2018

Aprovado: 14.01.2019 